\title{
Bile duct stone extraction under endoscopic ultra- sound guidance without fluoroscopy or contrast injection
}

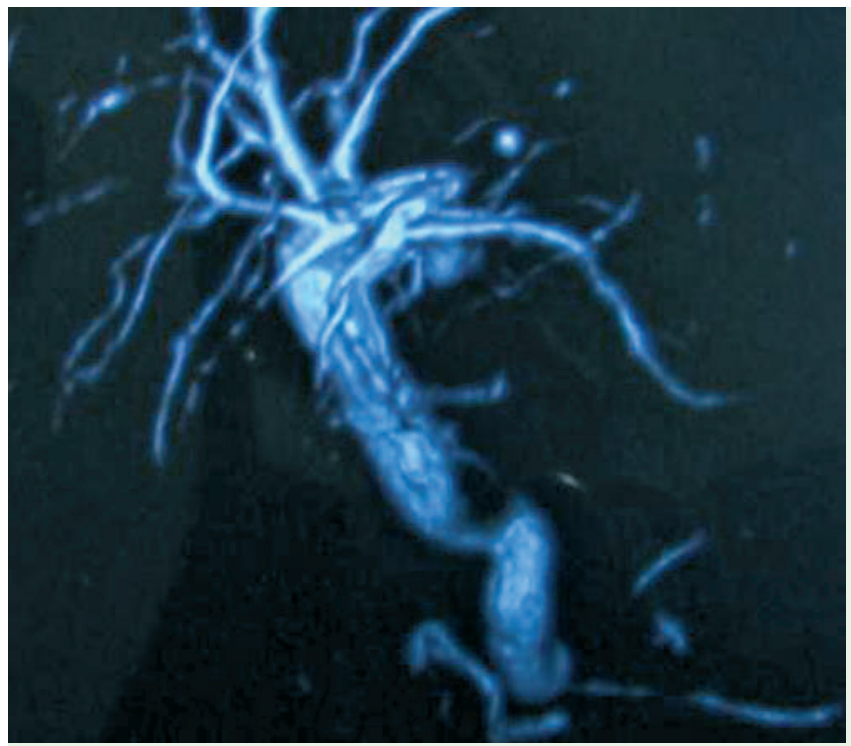

Fig. 1 Magnetic resonance imaging view of a distal common bile duct stone.

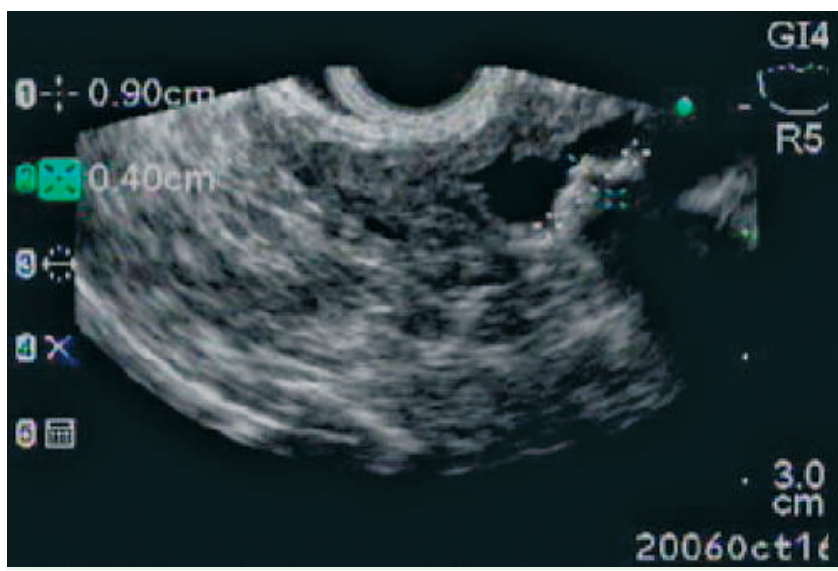

Fig. 2 Endoscopic ultrasound (EUS) demonstrated a stone in the distal common bile duct.

A 57-year-old woman with an allergy to iodinated contrast presented with intermittent right upper quadrant pain. Laboratory test results were as follows: total bilirubin $4 \mathrm{mg} / \mathrm{dL}$, alkaline phosphatase $164 \mathrm{mg} / \mathrm{dL}$, and normal amylase, aspartate transaminase, and alanine transaminase levels. A solitary $1-\mathrm{cm}$ calculus was identified in the distal common bile duct on magnetic resonance imaging ( Fig. 1); linear-array endosonography confirmed the presence of a $0.9-\mathrm{cm}$ calculus ( Fig. 2). Using a needle-knife, a 0.035 -inch guide wire, and a $12-\mathrm{mm}$ extraction balloon (all Boston Scientific, Natick, Massachusetts, USA), the bile duct was cannulated, the papilotomy exten-

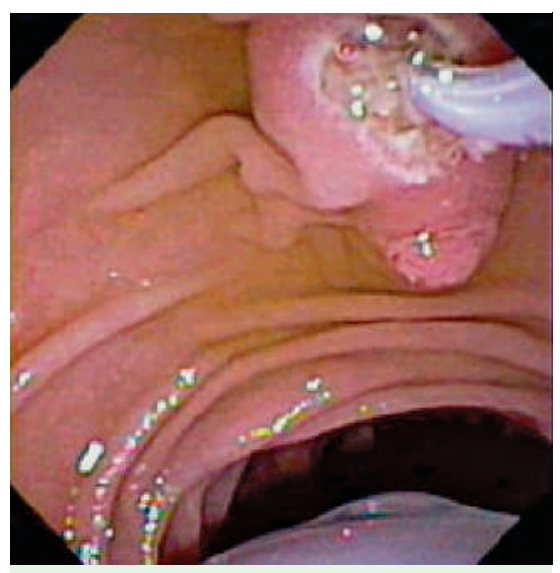

Fig. 3 A fistulotomy was performed under EUS guidance.

oids have been administered, delaying emergency therapeutic interventions in patients with serious conditions such as severe cholangitis or gallstone pancreatitis [1-3]. Fluoroscopy is also expensive and is a limited resource, given that its availability is often controlled by radiology departments. At the same time, EUS is becoming widely available and its range of indications is expanding [4]. We have demonstrated the feasibility of perfoming therapeutic interventions in the bile duct under EUS guidance alone, without fluoroscopy and contrast injection. This strategy has potential applications in pregnant women requiring therpaeutic interventions in the bile duct, in patients with contrast allergy who require emergency ERCP, and also in patients with bile duct abnormalities identified at EUS in whom an additional ERCP could be avoided using this technique [5].

Endoscopy_UCTN_Code_TTT_1AS_2AD Endoscopy_UCTN_Code_TTT_1AR_2AH

E. L. A. Artifon ${ }^{1}$, A. Kumar², S. Marques ${ }^{1}$, S. Ishioka ${ }^{1}$, P. Sakai ${ }^{3}$, M. S. Bhutani ${ }^{4}$ ded, and the stone extracted, all unde endoscopic ultrasound (EUS) guidance ( $\bullet$ Fig. 3,4). Standard cannulation under EUS guidance was unsuccessful, probably due to the presence of stone in the distal common bile duct/ampulla. There were no complications resulting from the endocopic intervention. The patient underwent an uneventful laparoscopic cholecystectomy and no residual stones were noted at intraoperative cholangiography. The injection of contrast during endoscopic retrograde cholangiopancreatography (ERCP) has been linked to postERCP pancreatitis. In addition, in patients with contrast allergy, ERCP might have to be delayed for up to 12 hours until ster- 


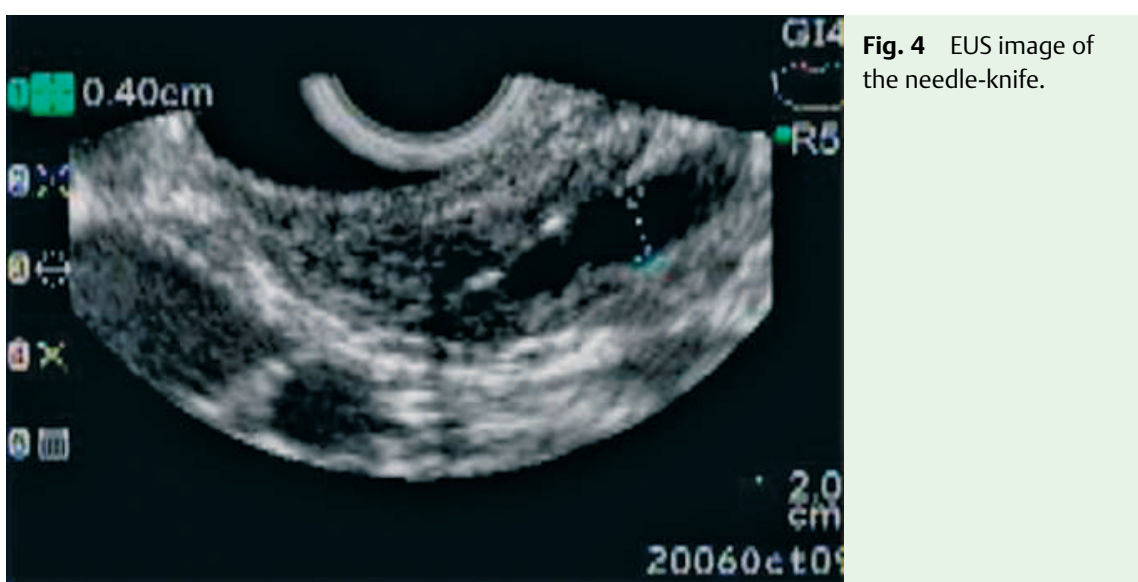

1 GI Endoscopy Division, University of Sao Paulo Medical School, Sao Paulo, Brazil

2 Department of Gastroenterology and Hepatology, Northport VA Medical Center and Stony Brook University, Northport, New York, USA

3 Gl Endoscopy Unit, Hospital Das Clinicas, Sao Paulo, Brazil

4 MD Anderson, Gastroenterology and Hepatology, Houston, Texas, USA
Bibliography

DOI 10.1055/s-2007-966551

Endoscopy 2008; 40: 13-14

(c) Georg Thieme Verlag KG Stuttgart · New York . ISSN 0013-726X

Corresponding author

\section{A. Kumar, MD}

Northport VA Medical Center

79 Middleville Road

Northport

New York 11790

Fax: +1-631-486-6113

atul.kumar2@va.gov 